\title{
Barriers to Use of Remote Monitoring Technologies Used to Support Patients With COVID-19: Rapid Review
}

Elizabeth Houlding ${ }^{1,2,3}$, HBsc; Kedar K V Mate ${ }^{3}, \mathrm{PhD}, \mathrm{MScPT}$; Kim Engler ${ }^{3}, \mathrm{PhD}$; David Ortiz-Paredes ${ }^{3}, \mathrm{MD}$, MSc; Marie-Pascale Pomey ${ }^{4,5}$, MD, PhD; Joseph Cox $^{1,3,6}$, MD, MSc; Tarek Hijal ${ }^{7}$, MD, MSc, CM; Bertrand Lebouché ${ }^{1,3,8}$, $\mathrm{MD}, \mathrm{PhD}$

\footnotetext{
${ }^{1}$ Chronic Viral Illness Service, Royal Victoria Hospital, McGill University Health Centre, Montréal, QC, Canada

${ }^{2}$ Department of Physical Therapy, Faculty of Medicine, University of Toronto, Toronto, ON, Canada

${ }^{3}$ Centre for Outcomes Research and Evaluation, Research Institute of the McGill University Health Centre, Montréal, QC, Canada

${ }^{4}$ Centre de recherche du Centre Hospitalier de l'Université de Montréal, Montréal, QC, Canada

${ }^{5}$ Département de gestion, évaluation et politique de santé, École de santé publique de l'Université de Montréal, Montréal, QC, Canada

${ }^{6}$ Department of Epidemiology and Biostatistics, Faculty of Medicine, McGill University, Montréal, QC, Canada

${ }^{7}$ Division of Radiation Oncology, McGill University Health Centre, Montréal, QC, Canada

${ }^{8}$ Department of Family Medicine, McGill University, Montréal, QC, Canada
}

\section{Corresponding Author:}

Bertrand Lebouché, MD, PhD

Chronic Viral Illness Service

Royal Victoria Hospital

McGill University Health Centre

Local D02.4110, Glen Site

1001 Décarie Blvd

Montréal, QC, H4A 3J1

Canada

Phone: 15143987375

Email: bertrand.lebouche@gmail.com

\section{Abstract}

Background: The COVID-19 pandemic has acted as a catalyst for the development and adoption of a broad range of remote monitoring technologies (RMTs) in health care delivery. It is important to demonstrate how these technologies were implemented during the early stages of this pandemic to identify their application and barriers to adoption, particularly among vulnerable populations.

Objective: The purpose of this knowledge synthesis was to present the range of RMTs used in delivering care to patients with COVID-19 and to identify perceived benefits of and barriers to their use. The review placed a special emphasis on health equity considerations.

Methods: A rapid review of published research was conducted using Embase, MEDLINE, and QxMD for records published from the inception of COVID-19 (December 2019) to July 6, 2020. Synthesis involved content analysis of reported benefits of and barriers to the use of RMTs when delivering health care to patients with COVID-19, in addition to health equity considerations.

Results: Of 491 records identified, 48 publications that described 35 distinct RMTs were included in this review. RMTs included use of existing technologies (eg, videoconferencing) and development of new ones that have COVID-19-specific applications. Content analysis of perceived benefits generated 34 distinct codes describing advantages of RMTs, mapped to 10 themes overall. Further, 52 distinct codes describing barriers to use of RMTs were mapped to 18 themes. Prominent themes associated with perceived benefits included a lower burden of care (eg, for hospitals, health care practitioners; 28 records), reduced infection risk $(n=33)$, and support for vulnerable populations $(n=14)$. Prominent themes reflecting barriers to use of RMTs included equity-related barriers (eg, affordability of technology for users, poor internet connectivity, poor health literacy; $n=16$ ), the need for quality "best practice" guidelines for use of RMTs in clinical care $(n=12)$, and the need for additional resources to develop and support new technologies $(n=11)$. Overall, 23 of 48 records commented on equity characteristics that stratify health opportunities and outcomes, including general characteristics that vary over time (eg, age, comorbidities; $n=17)$, place of residence ( $n=11$ ), and socioeconomic status $(n=7)$. 
Conclusions: Results of this rapid review highlight the breadth of RMTs being used to monitor and inform treatment of COVID-19, the potential benefits of using these technologies, and existing barriers to their use. Results can be used to prioritize further efforts in the implementation of RMTs (eg, developing "best practice" guidelines for use of RMTs and generating strategies to improve equitable access for marginalized populations).

(JMIR Mhealth Uhealth 2021;9(4):e24743) doi: $\underline{10.2196 / 24743}$

\section{KEYWORDS}

remote monitoring; technology; COVID-19, telehealth; asynchronous technology; synchronous technology; mHealth; monitoring; review; barrier; benefit; equity

\section{Introduction}

Delivering health care in the context of the COVID-19 pandemic is uniquely challenging [1]. The virus is highly contagious, potentially fatal, and symptoms that present early in the course of the illness can be mild and nonspecific [2]. Virulence of SARS-CoV-2 in health settings places health care providers and patients without COVID-19 at increased risk of contracting the illness [2]. The need to provide health care services while limiting in-person interaction places an enormous burden on already overwhelmed health systems.

Some models and technologies for delivering health care remotely existed prior to the COVID-19 pandemic. For instance, video consultation is commonly used to deliver health care services to rural and remote communities [3]. These technologies were used for a diversity of needs, including those who might otherwise have difficulty accessing expertise and health care (eg, due to remote location) [4,5]. Further, more recent public health crises of infectious diseases, including the 2002 severe acute respiratory syndrome epidemic, the $2009 \mathrm{H} 1 \mathrm{~N} 1$ pandemic, and the 2015 Ebola epidemic, highlighted the pivotal role remote technologies can play in delivering health care [6-8]. Within a short span of a few weeks, these technologies were at the forefront and were a critical method of offering care services.

To adequately address the challenges of the COVID-19 pandemic, unprecedented deployment of remote monitoring technologies (RMTs) is underway $[9,10]$. Due to a lack of consensus on the definition of RMTs, we took a broad scope and included any technology that facilitates communication between the health care team and patients [11]. RMTs can be categorized as "synchronous," where communication occurs in "real time," such as in videoconferencing, and "asynchronous," where there is a potential expected time delay in communication, such as email or SMS text message $[11,12]$. Both these forms of RMT could be delivered through a broad range of devices (eg, app on phone, wearable technology). RMTs at times reflect technology that is commonplace (eg, phone call, app on smartphone) or specialist in purpose (eg, oxygen saturation monitor, specific cell phone app). Further, RMTs have been used for a variety of purposes in health care. This has included monitoring symptoms, illness severity, and adherence to inform and deliver treatment [7].

In the context of the present pandemic, RMTs can be used when delivering health care to those with (eg, monitoring severity of illness in those with the diagnosis) or without diagnoses of COVID-19 (eg, delivering primary health care via telephone to

reduce likelihood of COVID-19 transmission). Understanding the use of RMTs for the treatment of COVID-19 is particularly pertinent in the context of an emergent pandemic and will be the focus of the present research.

In an early review of health technologies used to address COVID-19, Ming et al [9] described 110 COVID-19 asynchronous technologies including 17 that monitored patients remotely. The authors reported on the benefits of mobile phone apps, including allowing patients to self-monitor their symptoms and informing triage decisions regarding the need to access tertiary care. This use of RMTs could presumably reduce burden on hospital emergency departments. This study highlighted concerns regarding patient confidentiality and data security when using such mobile apps. Another narrative review described 17 different wearable technologies designed to remotely monitor COVID-19 signs and symptoms [10]. These devices included take-home electrocardiograms, blood pressure monitors, pulse oximeters, thermometers, and stethoscopes. These technologies allowed relevant diagnostic information to be collected. Further, use of these technologies helped optimize patient comfort and convenience while reducing the risk of COVID-19 transmission in the hospital setting and the need for hospital resources to be directed to those with milder symptoms. This review identified challenges in implementation, with a focus on technology-specific limitations-for instance, thermometer inaccuracies due to changes in ambient temperature [10].

As the pandemic develops, there will be waves of new technologies that are developed continuously to meet the emerging challenges. Some of these technologies are here to stay and could be available for future infectious diseases or be part of the routine care delivery model. Specific benefits or disadvantages of RMTs may fluctuate in relevance over time. This paper provides a snapshot that can be used as a baseline to track progress in this field over the course of the pandemic. This information will be relevant to innovators developing new RMTs for management of different health challenges, including treatment of vulnerable and marginalized patients with COVID-19.

Meeting needs of vulnerable populations requires consideration of equity in the present and for future health delivery endeavors. Equity considerations are those that focus on ways to decrease or eliminate differences in health outcomes and opportunities across groups [13]. It is vital to incorporate an equity lens since COVID-19 is more likely to impact marginalized populations [14-16]. Intentional efforts to reduce inequity are important in health care design. Considerations in inequity have been 
conceptualized using the PROGRESS-Plus acronym, which is used to identify characteristics that stratify health opportunities and outcomes [17].

Thus far, published research has presented a selection of health and resource benefits and highlighted some challenges of using RMTs. However, no paper has comprehensively summarized the wide range of advantages and challenges of technologies used to deliver health care in the context of the COVID-19 pandemic. Further, there are no reviews that specifically address equity of access to health care in the context of COVID-19.

A comprehensive review and summary of RMTs, including their advantages and challenges, together with future directions for innovation or improvement, will be a valuable asset for stakeholders. This information can be used to understand the breadth of available RMT options, anticipate and prevent difficulties, and improve equitable access to health care. This is particularly relevant early in the course of a pandemic when time-sensitive information is required.

The aim of this rapid review was to identify which RMTs have been deployed to support COVID-19 health care provision early in the pandemic, and identify the barriers to and benefits of their implementation. The review will emphasize equity considerations.

\section{Methods}

A rapid review was performed following the approach described by Cochrane Methods Group [18]. Rapid reviews offer a strategy to synthesize current knowledge in a timely manner "to meet time-sensitive decision-making needs" [1], which is valuable in contexts such as the COVID-19 global health crisis.

\section{Search Methods}

Ovid MEDLINE and Embase were searched for relevant publications published up until July 6, 2020. The search was initially informed by a preliminary unstructured search of QxMD [19] and MEDLINE (via PubMed). The search strategy (Multimedia Appendix 1) was developed using the COVID-19 keywords from the Canadian Agency for Drugs and Technologies in Health search strings [12].

\section{Inclusion Criteria}

Inclusion criteria for selection of publications were as follows: publications that discussed use of RMTs to deliver health care to patients with COVID-19; publications that referred to specific RMTs as opposed to general recommendations (this criterion was used to ensure barriers could be linked to a specific type of technology); and publications that were available in English, French, or Spanish.

\section{Exclusion Criteria}

Publications were excluded if the record only described RMTs used in contact tracing or epidemiological surveillance. This criterion was used because the focus of this review was on technologies that provide service or treatment to patients with COVID-19, rather than surveillance of the virus.

\section{Search Strategy}

An inclusive search strategy for different types of publications was used and included editorials, reviews, and letters to the editor. This inclusive strategy was adopted considering the novelty of COVID-19 (and hence dearth of published research-based studies). Further, the inclusive search strategy reflected the potential benefits of presenting a breadth of information at this early stage of the pandemic.

\section{Data Collection}

The primary author $(\mathrm{EH})$ reviewed the title and abstract of publications then extracted key information. Key information extracted included the year, journal, design, aim of the publication, nature of the RMT, whether the RMT was synchronous or asynchronous, information gathered via RMT, equity considerations, benefits of RMT use, and barriers to RMT use.

\section{Data Analysis}

Publications' results were synthesized using a "content analysis" approach [20]. A single reviewer (EH) developed a coding framework and mapped the RMTs used and variables monitored. Barriers and benefits of using RMT were coded inductively, and individual codes were grouped into overarching themes. A second reviewer (DOP) independently reviewed the developed coding framework against a random sample $(7 / 48,15 \%)$ of the publications. Further, the second reviewer coded this sample of publications against the finalized coding framework. All discrepancies (7\% discrepancy rate) in the coding framework or coding were settled by consensus-based discussion.

To ensure explicit consideration of health equity, relevant considerations were mapped deductively to the PROGRESS-Plus acronym [17]. The PROGRESS-Plus acronym refers to consideration of the following: place of residence, race or ethnicity or culture or language, occupation, gender or sex, religion, education, socioeconomic status, social capital, and "plus"-referring to personal characteristics associated with discrimination, features of relationships, and time-dependent relationships [17].

\section{Results}

\section{Results of Database Search}

Of 767 records identified through MEDLINE and Embase searches, and 4 records identified through QxMD, 491 remained after duplicates were removed (Figure 1). After title and abstract screening, 406 records were excluded from the review. Upon full-text review, 37 of 85 records were excluded because they did not include health care for patients with COVID-19 ( $n=13)$, did not describe an RMT $(n=12)$, were epidemiological studies and/or only described contact tracing $(n=6)$, were not in English, Spanish, or French $(n=5)$, or were technical reports $(n=1)$. In total, 48 publications were included in the qualitative synthesis. 
Figure 1. PRISMA 2009 flow diagram. PRISMA: Preferred Reporting Items for Systematic Reviews and Meta-Analyses; RMT: remote monitoring technology.

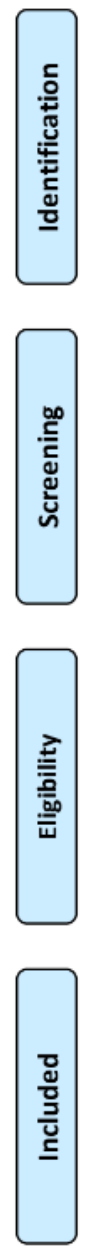

$$
\begin{gathered}
\text { Records identified through database } \\
\text { searching } \\
(\mathrm{n}=767)
\end{gathered}
$$

Additional records identified through other sources $(\mathrm{n}=4)$
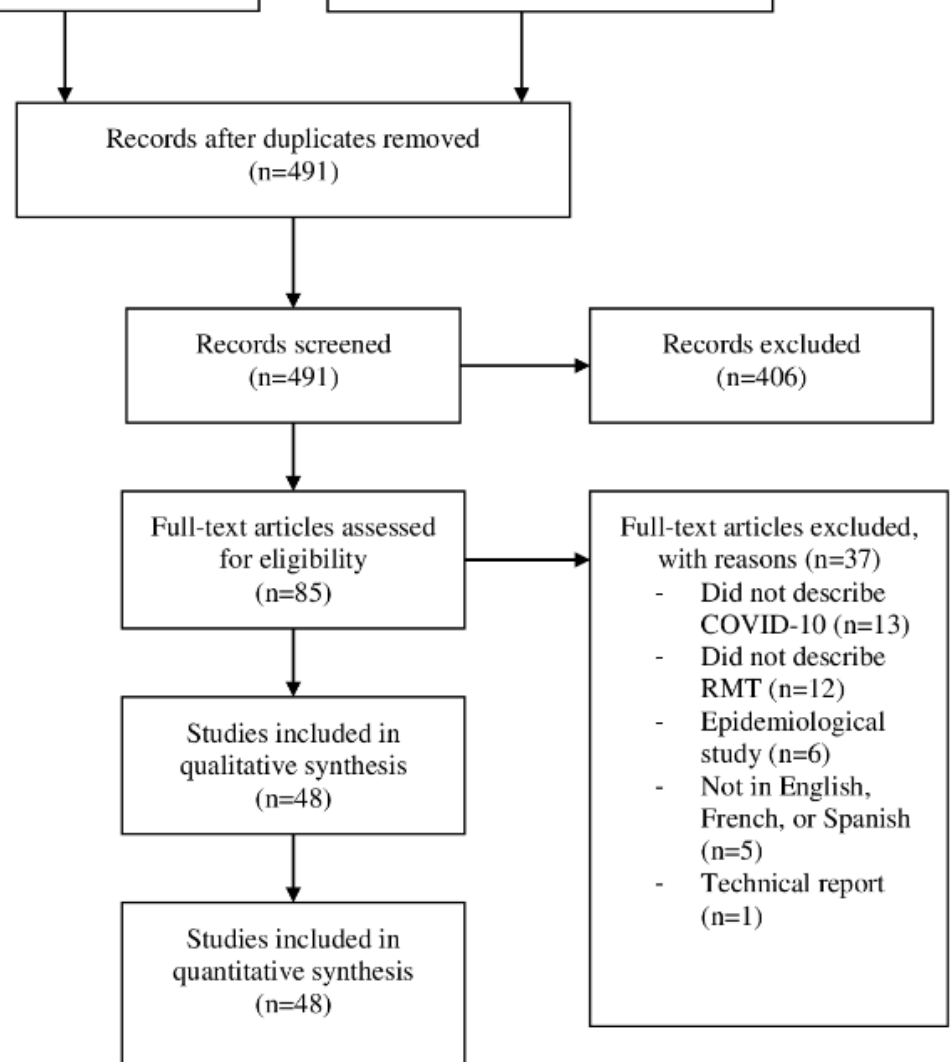

\section{Characteristics of Included Publications}

The most common types of publications identified were descriptive studies or proposals describing the implementation and development of RMTs $(n=18)$ and reviews of multiple RMTs ( $n=13)$. Letters to the editor $(n=9)$, editorials $(n=5)$, one retrospective cohort study, one protocol, and one case study were also included (Table 1). 
Table 1. Publication types and remote monitoring technologies included in the analysis.

\begin{tabular}{|c|c|}
\hline Publication type and ID & First author [refer \\
\hline \multicolumn{2}{|c|}{ Implementation and development } \\
\hline 2 & Annis [21] \\
\hline 4 & Bae [22] \\
\hline 10 & Faezipour [23] \\
\hline 13 & Ford [24] \\
\hline 25 & Krausz [25] \\
\hline 26 & Lam [12] \\
\hline 27 & Lui [26] \\
\hline 28 & Mann [27] \\
\hline 30 & Medina [28] \\
\hline 32 & Naik [29] \\
\hline 34 & Petrocelli [30] \\
\hline 35 & Saleem [31] \\
\hline 36 & Schinköthe [32] \\
\hline 39 & Song [33] \\
\hline 40 & Sossai [34] \\
\hline 42 & Timmers [35] \\
\hline 44 & Vaira [36] \\
\hline
\end{tabular}

\section{Implementation and development proposal}
38
Sharma [37]

\section{Retrospective cohort study}

47

$\mathrm{Xu}$ [38]

\section{Case study}

20

Huang [39]

Review

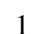

Alwashimi [40]

7

8

11

19

24
Crawford [41]

Ding [10]

Fagherazzi [42]

Hong [43]

Horowitz [44]

Kannampallil [45]

Keshvardoost [46]

Massaroni [47]
Remote monitoring technologies

\section{Mobile app}

Chat or telephone consultation, digital blood pressure monitor, digital thermometer, digital pulse oximeter

Mobile app diagnostic test

Chat or telephone or video consultation, data transmission, digital pulse oximeter, digital thermometer, electronic health record, mobile app, patient-accessed electronic health record

Chat or video consultation, electronic health record, mobile app, patient-accessed electronic health record, Voice over Internet Protocol technology, websites

Video consultation

Electronic health record, mobile apps

Electronic health record, video consultation

E-prescription, mobile app, telephone consultation

Closed-circuit television cameras, digital blood pressure monitor, digital electrocardiogram or heart rate monitor, digital end-tidal carbon dioxide monitor, digital pulse oximeter, digital respiratory rate monitor, mobile device video

Home diagnostic test

Automated SMS text messaging program

Electronic health record, mobile app

Video consultation

Chat or video consultation, mobile app

Mobile app

Home diagnostic test, telephone consultation

Wearable devices or biometric clothing

Chat or telephone consultation

Chat consultation, mobile app

Artificial intelligence-enabled request for assistance, chatbots, digital stethoscope, dronedelivered home diagnostic tests, glucometer, mobile app smart inhaler, video consultation, wearable devices or biometric clothing, website

Video consultation

Digital electrocardiogram or heart rate monitor, digital blood pressure monitor, digital respiratory rate monitor, digital pulse oximeter, digital stethoscope, digital thermometer, mobile device recording, wearable devices or biometric clothing

Chat or telephone or video consultation, e-prescription

E-prescription, mobile phone app, telephone consultation, video consultation

Mobile app diagnostic test, mobile app

Mobile app, wearable devices or biometric clothing

Electronic health record, telephone or video consultation

Laptop camera, mobile device camera, radar/Wi-Fi transmitter-receiver, smart mattress, tablet camera, wearable devices or biometric clothing

Mobile app 


\begin{tabular}{|c|c|c|}
\hline Publication type and ID & First author [reference] & Remote monitoring technologies \\
\hline 37 & Sharma [49] & $\begin{array}{l}\text { Digital blood pressure monitor, digital electrocardiogram or heart rate monitor, digital glu- } \\
\text { cometer, digital pulse oximeter, digital posture, digital respiratory rate monitor, digital } \\
\text { temperature monitor, digital weight monitor, patient-accessed electronic health record, video } \\
\text { consultation }\end{array}$ \\
\hline 41 & Thulesius [50] & Video consultation \\
\hline 45 & Watson [51] & Home diagnostic test, mobile app, video consultation \\
\hline 48 & Ye [52] & Telephone or video consultation \\
\hline \multicolumn{3}{|l|}{ Editorial } \\
\hline 6 & Cohen [53] & Tablet app, telephone consultation \\
\hline 9 & Edelman [54] & Electronic health record, video consultation \\
\hline 16 & Grenngalgh [55] & Video consultation \\
\hline 22 & John [56] & Video consultation \\
\hline \multicolumn{3}{|l|}{ Protocol } \\
\hline 15 & Greenhalgh [57] & Telephone or video consultation \\
\hline \multicolumn{3}{|l|}{ Letter to the editor } \\
\hline 3 & Anonymous [58] & Telephone consultation \\
\hline 5 & Barsom [59] & Electronic health records, patient-accessed electronic health record, tablet, video consultation \\
\hline 12 & Fitz [60] & Chat consultation \\
\hline 14 & Giansanti [61] & Mobile app, video consultation \\
\hline 17 & Hau [62] & Telephone or video consultation \\
\hline 21 & Jamil [63] & Telephone or video consultation \\
\hline 33 & Nair [64] & Electronic health record mobile app, telephone or video consultation \\
\hline 43 & Trethewey [65] & Telephone or video consultation \\
\hline 46 & Wei [66] & Video consultation \\
\hline
\end{tabular}

\section{Description of RMTs}

These publications identified 35 distinct types of RMTs ( 32 asynchronous and 3 synchronous; Table 2). Overall, 35 of the 48 studies identified synchronous technologies, including video $(n=25)$, telephone $(n=15)$, chat $(n=8)$, and mobile or cellular device video $(n=3)$ consultations. In total, 33 studies reported asynchronous technologies, including mobile or cellular apps for patients to manually enter their symptoms or education $(n=17)$, home diagnostic tests $(n=6)$, remote access to electronic health records by provider $(n=8)$, digital pulse oximeters $(n=5)$, biometric clothing $(n=5)$, and remote access to electronic health records by patient $(n=5)$. Data were collected through manual input by patients, caregivers, and health care practitioners $(n=45$; Multimedia Appendix 2), and automatically through the use of biosensor technology ( $n=22$; Multimedia Appendix 3). The most commonly reported manually inputted outcome measures were "symptoms" ( $\mathrm{n}=18)$, dyspnea or shortness of breath $(\mathrm{n}=7)$, pulse oximetry $(n=7)$, mental health $(n=7)$, temperature $(n=6)$, and presence or absence of fever $(n=6)$. The most frequently reported biosensor measures were temperature $(n=5)$ and cardiac activity (as measured by an electrocardiogram; $n=5$ ). 
Table 2. Summary of remote monitoring technologies grouped into synchronous or asynchronous.

\begin{tabular}{|c|c|}
\hline Type of remote monitoring technology & Total publications, $\mathrm{n}$ \\
\hline \multicolumn{2}{|l|}{ Asynchronous } \\
\hline Mobile or cellular app & 17 \\
\hline Electronic health record (eg, cloud based) & 8 \\
\hline Home diagnostic tests & 6 \\
\hline Digital (eg, Bluetooth) pulse oximeter & 5 \\
\hline Wearable device or biometric clothing & 5 \\
\hline Patient-accessed electronic health record & 5 \\
\hline Digital thermometer & 4 \\
\hline Digital blood pressure sensor & 4 \\
\hline Mobile or cellular app diagnostic test (acoustic signal, olfactory and gustatory test) & 3 \\
\hline Digital heart rate monitor, respiratory rate monitor, and electrocardiogram (eg, measure heart rate variability) & 3 \\
\hline Tablet (eg, iPads) may be used for video & 3 \\
\hline E-prescription & 3 \\
\hline Website to monitor symptoms & 2 \\
\hline Digital stethoscope & 2 \\
\hline Glucometer & 2 \\
\hline Data transmission technology & 2 \\
\hline Automated SMS text messaging program & 1 \\
\hline Chatbot, drone, artificial intelligence-enabled request for assistant, smart inhaler & 1 \\
\hline Closed-circuit television camera and digital end-tidal carbon dioxide monitor & 1 \\
\hline Digital weight and posture sensors & 1 \\
\hline Smart mattress & 1 \\
\hline Voice over Internet Protocol technology & 1 \\
\hline \multicolumn{2}{|l|}{ Synchronous } \\
\hline Video consultation & 25 \\
\hline Telephone consultation & 15 \\
\hline Chat consultation & 7 \\
\hline Mobile or cellular device video consultation & 2 \\
\hline
\end{tabular}

\section{Benefits of RMTs}

Almost all publications $(46 / 48,96 \%)$ provided some description of the reported benefits of RMTs. In total, 34 distinct codes were developed inductively from these documents (Multimedia Appendix 4). These were grouped into 10 themes (Table 3): "reduces infection risk" ( $\mathrm{n}=33$ articles), "reduces burden of care" (eg, limits hospital beds used; $n=28)$, "supports vulnerable populations" $(n=14)$, "reduces costs" $(n=12)$, "improves patient experience" ( $n=11)$, "promotes knowledge development" $(n=8)$, "facilitates navigation through health care system" $(\mathrm{n}=8)$, "improves health outcomes" $(n=6)$, "supports public health initiatives" ( $n=5)$, and "technology-specific benefits" $(n=4)$.

The most common theme, "reduces infection risk," included 3 codes: "reduces risk of transmission generally" $(\mathrm{n}=18)$, "reduces exposure of health care practitioners" $(n=11)$, and "reduces cross-contamination or clustering" $(n=10)$. A total of 28 codes were mapped to the theme "reduces burden of care," notably that RMTs "reduce the burden on hospitals" (eg, limit hospital beds used; $n=17$ ), "provide continuous accessible data or monitoring" $(\mathrm{n}=12)$, and "reduce burden of time on health care workers" (eg, using asynchronous technology or reducing burden overall; $n=6$ ). In addition, 5 codes were mapped to the theme "RMTs support vulnerable populations," including "reduces need for transfer of vulnerable patients" $(n=6)$ and "supports patient mental health" (eg, relieves stress, supports anxious patients; $n=5)$. A total of 3 codes were mapped to the theme "reduces cost," notably "reduces health care system or public health agency costs" $(\mathrm{n}=12)$. A total of 3 codes were mapped to the theme "improves patient experience," including "improves patient initiative, engagement, autonomy, or self-management" $(n=5)$. In addition, two codes were mapped to "facilitates navigation through the health care system," notably "facilitated follow-up, continuity of care, or linkage to care" $(\mathrm{n}=5)$. The theme "improves health outcomes" contained only one code, "provides rapid identification of infection or 
clinical deterioration for timely treatment of COVID-19" $(n=6)$. Finally, the theme "supports public health initiatives" contained 2 codes, including "delivers educational messages" (eg, fights disinformation or the "infodemic"; $n=5$ ). All other codes were noted by $<5$ publications.

Table 3. Perceived benefits of remote monitoring technologies for patients with COVID-19.

\begin{tabular}{ll}
\hline Themes & Total publications, $\mathrm{n}$ \\
\hline Reduces infection risk & 33 \\
Reduces burden of care & 28 \\
Supports vulnerable populations & 14 \\
Reduces costs & 12 \\
Improves patient experience & 11 \\
Promotes knowledge development & 8 \\
Facilitates navigation through health care system & 8 \\
Improves health outcomes & 6 \\
Supports public health initiatives & 5 \\
Technology-specific benefits & 4 \\
\hline
\end{tabular}

\section{Barriers to Using RMTs}

Many publications $(38 / 48,80 \%)$ reported barriers, challenges, and/or concerns regarding implementation of RMTs (Table 4). In all, 54 distinct codes were developed inductively (Multimedia Appendix 5) and mapped to 15 themes: "equity-related barriers" $(\mathrm{n}=16)$, "a lack of RMT implementation guidelines and research" $(\mathrm{n}=12)$, "resources required for technology development and implementation" $(\mathrm{n}=11)$, "challenging patient experiences of RMTs" (n=10), "confidentiality-related concerns" $(n=10)$, "workforce training" ( $\mathrm{n}=8)$, "quality of information" $(\mathrm{n}=8)$, "communication-related barriers" $(\mathrm{n}=7)$, "ethical concerns with RMTs" (n=7), "policy requirements" $(n=7)$, "quality of care concerns" ( $n=4)$, "technology-specific barriers" $(n=3)$, "technology integration-related barriers" $(n=2)$, and "financial barriers" $(n=2)$. A total of 8 codes were mapped to the theme "equity-related barriers," including "lack of access to RMTs in low-resource settings" (eg, patients experiencing homelessness, neighborhoods without access to libraries, households without internet or devices, low-income communities unable to afford RMTs or share RMTs; n=8), "low network quality or internet connectivity or bandwidth," which can impact quality of care $(n=6)$, and "low patient health literacy" $(n=5)$. A total of 5 codes were mapped to the theme "a lack of RMT implementation guidelines and research," with 9 publications reporting a "paucity of high-quality data or guidelines to support effective and safe RMT, particularly in acute care." A total of 7 codes were mapped to the theme "resources required for technology development and implementation," including "inadequate control of patient flow with some RMTs" (eg, the fluctuating recruitment of patients should be matched with staffing; $n=5$ ). A total of 4 codes were mapped to the theme "challenging patient experiences of RMTs," including "the complexity or intrusiveness of switching to online consultation or remote monitoring and disruption to patient or worker processes and routines" $(n=5)$. A total of 3 codes were mapped to the theme "confidentiality-related barriers," including "the need to address privacy concern when implementing RMTs" $(n=9)$. A total of 3 codes were mapped to the theme "workforce training," including "the need for additional workforce education and training in use of RMTs" ( $n=6)$. A total of 2 codes were mapped to the theme "quality of information," including "issues regarding the quality of health information reported or collected" (eg, self-reporting; n=6). Finally, 3 codes were mapped to the theme "ethical concerns with RMTs," of which the majority $(n=5)$ of the publications reported general ethical concerns. All other codes were reported by $<5$ publications. 
Table 4. Perceived barriers to using remote monitoring technologies for patients with COVID-19.

\begin{tabular}{ll}
\hline Themes & Total publications, $\mathrm{n}$ \\
\hline Equity-related barriers & 16 \\
A lack of remote monitoring technology implementation guidelines and research & 12 \\
Resources required for technology development and implementation & 11 \\
Challenging patient experiences of remote monitoring technologies & 11 \\
Confidentiality-related barriers & 10 \\
Workforce training & 8 \\
Quality of information & 8 \\
Communication-related barriers & 7 \\
Ethical concerns with remote monitoring technologies & 7 \\
Policy requirements & 7 \\
Quality of care & 4 \\
Technology-specific barriers & 3 \\
Technology integration-related barriers & 2 \\
Financial barriers & 2 \\
\hline
\end{tabular}

\section{Equity Factors}

Equity groups were mapped deductively to the PROGRESS-Plus acronym (Table 5). Several publications $(n=23)$ noted how remote monitoring provided information on characteristics of populations that could stratify health opportunities and outcomes (Multimedia Appendix 6). The most frequently reported characteristic was the "Plus" code $(n=17)$. This "Plus" code refers to specific patient populations (ie, patients who distrust the health care system, those with chronic conditions or comorbidities, immune-suppressed patients, pregnant women, acutely unwell patients, patients with cognitive impairment, nonadherent patients, seniors, and youth). The next most common PROGRESS-Plus code was "place of residence." A total of 11 publications commented on patient place of residence as impacting the implementation of RMTs, including rural and remote residences, nursing homes, or homelessness. A total of 7 publications reported socioeconomic factors, such as a lack of community funding in low- and middle-income countries, lack of access to technology, or low-income patients. A total of 3 publications reported on race or ethnicity or culture or language, occupation, and gender or sex, respectively. Occupations considered were frontline workers and veterans. Finally, in terms of PROGRESS-Plus equity considerations, 2 publications commented on education, specifically the health literacy level of patients, which could impact their ability to understand infection control information or assess the quality of unregulated health information. Only one publication commented on social capital and none on religion. 
Table 5. PROGRESS-Plus themes.

\begin{tabular}{lll}
\hline Theme & Total publications, $\mathrm{n}$ & Demonstrative quote \\
\hline Place of residence & 11 & $\begin{array}{l}\text { "It is also important to consider that some countries may not have the technological in- } \\
\text { frastructure to support [digital health]. Furthermore, there will be a significant proportion } \\
\text { of the population who will not have access to technology or internet connectivity" [40] }\end{array}$
\end{tabular}

Race or ethnicity or culture 3 or language

Occupation

Religion

Education

Socioeconomic status
0
Social capital

Plus
"Mounting evidence suggests that the COVID-19 pandemic has far greater associated morbidity and mortality in racialized groups that struggle with poverty and poor access to health care; the pandemic has also been suggested to compound pre-existing inequities. Similarly, there has been a lack of attention to health equity in the development of digital health solutions" [41]

"Individuals exposed to the public (such as transit workers and police/force/emergency medical services (EMS) workers) and cultural settings with risk for infection (eg, multifamily settings with multiple house members working with high risk for COVID-19 exposure settings), in addition to those in meat packing plants or the front-line grocery store workers, are especially in the high-risk exposure category. This additionally emphasizes the need for developing testing models of the breathing app from the breathing sound database." [23]

"In Dover and Belon's model, which informs the foundation of the [Digital Health Equity Framework], the process of social stratification within economic and cultural social contexts refers to the hierarchical allocation and unequal distribution of power, prestige, and resources; this stratification assigns individuals to a social location, which is defined by intersectional factors such as race, age, income, geography, rurality, gender, ability, and occupation as well as other social factors" [41]

$\sim^{\mathrm{a}}$

"Our findings suggest that even in high-income countries, such as the [United Arab Emirates] with modern digital access and high general literacy rates, health literacy may pose an obstacle for the adoption of telemedicine. It is, therefore, critical for countries worldwide to improve health literacy to optimize patient access and engagement in this expanding world of digital medical care delivery." [64]

"Lastly, some developing countries face major obstacles to the effective delivery of digital health solutions in rural and remote locations, such as incomplete or insufficient basic digital infrastructures (eg, computers, internet networks, and electricity), lack of sustainable funding to develop, operate, and maintain digital platforms, and high telecommunication costs" [42]

See "Gender or sex" above [41]

"The network has focused on groups particularly vulnerable to severe symptoms of COVID-19, including the elderly, pregnant women, children, and patients with chronic health problems." [43]

${ }^{\mathrm{a}}$ Not available.

\section{Discussion}

\section{Principal Findings}

A rapid review was conducted to present the different types of RMTs deployed in response to the COVID-19 pandemic, the perceived benefits of these technologies, and the perceived barriers or challenges to their use in clinical work. There was special emphasis placed on equity considerations.

Results indicate that many different RMTs are used when providing health care to patients with COVID-19. Most RMTs mirrored the real-time interpersonal communication processes involved in prepandemic care, except that the care was being delivered with physical distance-for instance, the use of videoconferencing $(25 / 48,52 \%)$ and teleconferencing $(15 / 48$, $31 \%$ ) rather than in-person appointments, and accessing medical records remotely $(8 / 48,17 \%)$ rather in the office. Video was likely favored because of the substantial advantage of being able to use nonverbal cues and assessment. These innovations were pertinent to monitoring, triage, and diagnosis (eg, symptom tracking using mobile apps).

\section{Benefits of RMTs and Implications}

The most common reported benefit of RMTs was that it reduced the risk of transmission of COVID-19 ( $\mathrm{n}=18)$, including to health care practitioners $(\mathrm{n}=10)$. This is unsurprising, considering that concern about managing infection rates is one of the forces driving rapid implementation of RMTs across many specialties [67]. Further, with increasing pressure on the health care system, RMTs could aid in reducing the burden on hospitals ( $n=17)$, health care system costs $(n=10)$, and the burden of time of health care practitioners $(n=16)$.

Use of these RMTs began or substantially increased in response to COVID-19. If perceived advantages are borne out, this may lead to wider adoption beyond the pandemic.

There may be several implications when considering the breadth of RMTs already in use. First, both health care providers and 
patients may become accustomed to the remote modality and its benefits, including increased convenience, meaning that RMT use could continue beyond the duration of the pandemic. Health care during the pandemic has increased patient involvement in their own care (eg, symptom monitoring). This may lead to a permanent shift in health care culture, in which patients' active participation is incorporated into the health provision of other conditions. The development of health-related software for signs and symptom monitoring and triage could also continue and become refined and expand the tools through which quality health care is delivered. When considering whether or which changes might endure, it might be helpful to distinguish between advantages of RMTs that are only relevant to COVID-19 infection risk and those where the benefits might persist beyond COVID-19 (eg, widespread use of health-related apps to better monitor symptoms for other conditions). It is possible and likely that the processes surrounding their use will be refined to address and reduce concerns and barriers.

\section{Barriers to Use of RMTs}

The most commonly reported barrier themes were a lack of guidance $(n=12)$ and increased resources needed $(n=11)$ for implementation, development, and use of RMTs to treat COVID-19. These barriers are likely due to the novel nature of COVID-19 and thus could become less relevant over time. Another main concern cited by several publications was that rigorous privacy and security settings would be necessary to protect patient information $(n=9)$. However, despite emphasizing the importance of privacy and security, only 5 publications of 18 describing implementation of a specific RMT reported on security and privacy features or policies of the software used [24-26,32,35]. Additionally, two publications noted that use of RMTs could break down the humanitarian core of care as well as patient-provider communication $[43,50]$. One way to promote effective patient communication is to design user-friendly technology with two-way communication [68]. Although patient involvement in technology development can be used to effectively tailor the technology to the specific needs of the patient [69], no publications reported this in practice. This is unfortunate considering the impact it can have on the success of an RMT [70]. Future technologies should involve rigorous user evaluation based on feedback from patients. The extent of patient involvement in RMT implementation should be thoroughly described to support use of the technology. Lastly, it will take time and resources to bring RMTs to scale; information regarding clinical utility and cost will help ascertain which should be prioritized for investment of resources to aid in this development.

\section{Equity Factors}

Equity factors also proved important to consider when implementing RMTs. Health interventions should be tailored according to population needs or they risk increasing health inequities [17]. The most common overall barrier theme was concerns regarding equitable use of RMTs $(n=15)$. This is concerning considering marginalized groups are already disproportionately impacted by COVID-19. There is a higher incidence of infection, as well as poorer outcomes, among racialized communities and ethnic minorities [71-73]. More than half of the included publications $(n=28)$ noted challenges that might be faced by minorities or emphasized the importance of training health practitioners in equitable digital health implementation and supporting low-income communities. Alternatively, possible benefits were reported in some papers $(\mathrm{n}=7)$, including the ability to support vulnerable populations - for example, medically vulnerable individuals, or those living in rural or remote communities. Overall, there appeared to be conflicting perspectives on whether RMTs would decrease or increase health inequities. There is evidence that intervention-generated inequities - those caused by use of interventions that provide limited benefit to vulnerable populations — can decrease health outcomes among marginalized groups [13]. It is important to track characteristics that may stratify health outcomes in order to assess which RMTs will benefit vulnerable populations. Overall, 23 of 48 total papers (48\%) and 7 of 18 (39\%) implementation and development papers reported on characteristics of populations that stratify health outcomes. It is critical that an increasing number of publications start to analyze data based on characteristics that influence equitable outcomes to better support vulnerable groups and reduce health inequities.

\section{Limitations}

This work has several time-related limitations due to the rapid nature of this review. Only one screener $(\mathrm{EH})$ reviewed the titles, abstracts, and full texts of the records and coded during the selection process. Further, given the delay between the use of an intervention and publication of its evaluation, the technologies presented here only reflect what was used during a specific window of time and as new technologies are rapidly developed and implemented, there will be a need to reassess new and emerging benefits of and barriers to patient care. Further periodic reviews should be conducted to assess how the use of RMTs evolves. In addition, the quality of the analysis was limited. Furthermore, the frequency of reporting does not necessarily equal the magnitude of importance or the impact on outcomes for patients. Lastly, certain papers reported on multiple technologies but did not provide benefits and barriers specific to each RMT individually, which limits the generalizability of our findings. As such, most benefits and barriers reported in this paper were categorized generally as applicable to both synchronous and asynchronous RMTs. Undoubtedly, many of these benefits and barriers will be more or less relevant depending on the technology (eg, reduced isolation is more applicable for treatment via video consultation than for use of a digital pulse oximeter). Future reviews should focus on separating benefits and barriers according to technology type if possible.

\section{Conclusion}

This rapid review summarizes RMTs that were used in the early stages of the COVID-19 pandemic and provides insights on the benefits these technologies could provide for future use. It also highlights perceived barriers to implementation of RMTs that should be addressed in ongoing development projects. Guidelines and policies developed for implementing RMTs ought to be mindful of the identified barriers. RMTs have an important role to play in supporting patients and communities 
through these unprecedented times. One key recommendation is to establish best practices in the development of RMTs so

they are both equitable and effective going forward.

\section{Acknowledgments}

BL received the Canadian Institutes for Health Research (CIHR), Strategy for Patient-Oriented Research Mentorship Chair in Innovative Clinical Trials for HIV Care. KM, a postdoctoral fellow, is funded by this mentorship chair. BL is also supported by a career award LE 250 from Quebec's Ministry of Health for researchers in Family Medicine.

Our work is one of the critical research programs being supported by the McGill Interdisciplinary Initiative in Infection and Immunity (MI4), with seed funding from the McGill University Health Centre Foundation.

This work is supported by CIHR funding awarded to MPP and BL ("Real time evaluation of the deployment of connected technologies and of the partnership of services and care during the COVID-19 sanitary crisis - the Techno-COVID-Partnership program,” 2020-05-12 Operating Grant: COVID-19 May 2020 Rapid Research Funding Opportunity - grant 444186 \#).

\section{Authors' Contributions}

$\mathrm{EH}, \mathrm{KM}$, and BL all contributed to the conceptualization of this project. EH developed the search strategy, completed title and abstract screening and full-text review. EH collected and analyzed the data from included publications, which were verified by DOP. EH prepared the written manuscript. KM, KE, DOP, MPP, JC, TH, and BL reviewed the manuscript and provided feedback.

\section{Conflicts of Interest}

Author EH is employed by author BL. Author TH is the cofounder of Opal, a patient portal and app. The other authors have no conflicts to declare.

\section{Multimedia Appendix 1}

COVID-19 remote monitoring search strategy: July 6, 2020.

[DOCX File, 17 KB-Multimedia Appendix 1]

\section{Multimedia Appendix 2}

Physiological parameters and symptoms that are manually inputted into remote monitoring technologies.

[DOCX File, $17 \mathrm{~KB}-$ Multimedia Appendix 2]

\section{Multimedia Appendix 3}

IDs of records that reported automatically recorded biosensor outcome measures.

[DOCX File, 15 KB-Multimedia Appendix 3]

\section{Multimedia Appendix 4}

IDs of records that reported benefits of remote monitoring technologies.

[DOCX File, 18 KB-Multimedia Appendix 4]

\section{Multimedia Appendix 5}

IDs of records that reported barriers to use of remote monitoring technologies.

[DOCX File, 25 KB-Multimedia Appendix 5]

\section{Multimedia Appendix 6}

IDs of records that identified characteristics that stratify health opportunities or outcomes mapped to the PROGRESS-Plus framework.

[DOCX File, 13 KB-Multimedia Appendix 6]

\section{References}

1. Hartling L, Guise J, Kato E, Anderson J, Belinson S, Berliner E, et al. A taxonomy of rapid reviews links report types and methods to specific decision-making contexts. J Clin Epidemiol 2015 Dec;68(12):1451-62.e3. [doi:

10.1016/j.jclinepi.2015.05.036] [Medline: 26278023] 
2. Esakandari H, Nabi-Afjadi M, Fakkari-Afjadi J, Farahmandian N, Miresmaeili S, Bahreini E. A comprehensive review of COVID-19 characteristics. Biol Proced Online 2020 Aug 4;22(1):19 [FREE Full text] [doi: 10.1186/s12575-020-00128-2] [Medline: $\underline{32774178]}$

3. Pignatiello A, Teshima J, Boydell KM, Minden D, Volpe T, Braunberger PG. Child and youth telepsychiatry in rural and remote primary care. Child Adolesc Psychiatr Clin N Am 2011 Jan;20(1):13-28. [doi: 10.1016/i.chc.2010.08.008] [Medline: 21092909]

4. Vegesna A, Tran M, Angelaccio M, Arcona S. Remote Patient Monitoring via Non-Invasive Digital Technologies: A Systematic Review. Telemed J E Health 2017 Jan;23(1):3-17 [FREE Full text] [doi: 10.1089/tmj.2016.0051] [Medline: 27116181]

5. Queirós A, Alvarelhão J, Cerqueira M, Silva A, Santos M, Pacheco Rocha N. Remote Care Technology: A Systematic Review of Reviews and Meta-Analyses. Technologies 2018 Feb 10;6(1):22. [doi: 10.3390/technologies6010022]

6. Anderson RM, Fraser C, Ghani AC, Donnelly CA, Riley S, Ferguson NM, et al. Epidemiology, transmission dynamics and control of SARS: the 2002-2003 epidemic. Philos Trans R Soc Lond B Biol Sci 2004 Jul 29;359(1447):1091-1105 [FREE Full text] [doi: 10.1098/rstb.2004.1490] [Medline: 15306395]

7. Ohannessian R. Telemedicine: Potential applications in epidemic situations. European Research in Telemedicine / La Recherche Européenne en Télémédecine 2015 Sep;4(3):95-98. [doi: 10.1016/j.eurtel.2015.08.002]

8. Tom-Aba D, Nguku PM, Arinze CC, Krause G. Assessing the Concepts and Designs of 58 Mobile Apps for the Management of the 2014-2015 West Africa Ebola Outbreak: Systematic Review. JMIR Public Health Surveill 2018 Oct 29;4(4):e68 [FREE Full text] [doi: 10.2196/publichealth.9015] [Medline: 30373727]

9. Ming LC, Untong N, Aliudin NA, Osili N, Kifli N, Tan CS, et al. Mobile Health Apps on COVID-19 Launched in the Early Days of the Pandemic: Content Analysis and Review. JMIR mHealth uHealth 2020 Sep 16;8(9):e19796 [FREE Full text] [doi: 10.2196/19796] [Medline: 32609622]

10. Ding X, Clifton D, Ji N, Lovell NH, Bonato P, Chen W, et al. Wearable Sensing and Telehealth Technology with Potential Applications in the Coronavirus Pandemic. IEEE Rev Biomed Eng 2021;14:48-70. [doi: 10.1109/rbme.2020.2992838]

11. Verhoeven F, Tanja-Dijkstra K, Nijland N, Eysenbach G, van Gemert-Pijnen L. Asynchronous and synchronous teleconsultation for diabetes care: a systematic literature review. J Diabetes Sci Technol 2010 May 01;4(3):666-684 [FREE Full text] [doi: 10.1177/193229681000400323] [Medline: 20513335]

12. Lam PW, Sehgal P, Andany N, Mubareka S, Simor AE, Ozaldin O, et al. A virtual care program for outpatients diagnosed with COVID-19: a feasibility study. CMAJ Open 2020 May 23;8(2):E407-E413 [FREE Full text] [doi:

10.9778/cmajo.20200069] [Medline: $\underline{\text { 32447283] }}$

13. Lorenc T, Petticrew M, Welch V, Tugwell P. What types of interventions generate inequalities? Evidence from systematic reviews. J Epidemiol Community Health 2013 Feb 08;67(2):190-193. [doi: 10.1136/jech-2012-201257] [Medline: 22875078]

14. Walker RC, Tong A, Howard K, Palmer SC. Patient expectations and experiences of remote monitoring for chronic diseases: Systematic review and thematic synthesis of qualitative studies. Int J Med Inform 2019 Apr;124:78-85 [FREE Full text] [doi: 10.1016/j.ijmedinf.2019.01.013] [Medline: 30784430]

15. Crawford A, Serhal E. Digital Health Equity and COVID-19: The Innovation Curve Cannot Reinforce the Social Gradient of Health. J Med Internet Res 2020 Jun 02;22(6):e19361 [FREE Full text] [doi: 10.2196/19361] [Medline: 32452816]

16. Pandian PS. An Overview of Telemedicine Technologies for Healthcare Applications. In: Wearable Technologies: Concepts, Methodologies, Tools, and Applications. Hershey, PA, USA: IGI Global; 2018:732-759.

17. O'Neill J, Tabish H, Welch V, Petticrew M, Pottie K, Clarke M, et al. Applying an equity lens to interventions: using PROGRESS ensures consideration of socially stratifying factors to illuminate inequities in health. J Clin Epidemiol 2014 Jan;67(1):56-64. [doi: 10.1016/j.jclinepi.2013.08.005] [Medline: 24189091]

18. Garritty C, Gartlehner G, Nussbaumer-Streit B, King VJ, Hamel C, Kamel C, et al. Cochrane Rapid Reviews Methods Group offers evidence-informed guidance to conduct rapid reviews. J Clin Epidemiol 2021 Feb;130:13-22 [FREE Full text] [doi: 10.1016/j.jclinepi.2020.10.007] [Medline: 33068715]

19. QxMD. URL: https://qxmd.com/ [accessed 2021-02-21]

20. Elo S, Kyngäs H. The qualitative content analysis process. J Adv Nurs 2008 Apr;62(1):107-115. [doi: 10.1111/j.1365-2648.2007.04569.x] [Medline: 18352969]

21. Annis T, Pleasants S, Hultman G, Lindemann E, Thompson JA, Billecke S, et al. Rapid implementation of a COVID-19 remote patient monitoring program. J Am Med Inform Assoc 2020 Aug 01;27(8):1326-1330 [FREE Full text] [doi: 10.1093/jamia/ocaa097] [Medline: 32392280]

22. Bae YS, Kim KH, Choi SW, Ko T, Jeong CW, Cho B, et al. Information Technology-Based Management of Clinically Healthy COVID-19 Patients: Lessons From a Living and Treatment Support Center Operated by Seoul National University Hospital. J Med Internet Res 2020 Jun 12;22(6):e19938 [FREE Full text] [doi: 10.2196/19938] [Medline: 32490843]

23. Faezipour M, Abuzneid A. Smartphone-Based Self-Testing of COVID-19 Using Breathing Sounds. Telemed J E Health 2020 Oct 02;26(10):1202-1205. [doi: 10.1089/tmj.2020.0114] [Medline: 32487005]

24. Ford D, Harvey J, McElligott J, King K, Simpson KN, Valenta S, et al. Leveraging health system telehealth and informatics infrastructure to create a continuum of services for COVID-19 screening, testing, and treatment. J Am Med Inform Assoc 2020 Dec 09;27(12):1871-1877 [FREE Full text] [doi: 10.1093/jamia/ocaa157] [Medline: 32602884] 
25. Krausz M, Westenberg JN, Vigo D, Spence RT, Ramsey D. Emergency Response to COVID-19 in Canada: Platform Development and Implementation for eHealth in Crisis Management. JMIR Public Health Surveill 2020 May 15;6(2):e18995 [FREE Full text] [doi: $\underline{10.2196 / 18995}$ ] [Medline: $\underline{\text { 32401218] }}$

26. Liu Y, Wang Z, Ren J, Tian Y, Zhou M, Zhou T, et al. A COVID-19 Risk Assessment Decision Support System for General Practitioners: Design and Development Study. J Med Internet Res 2020 Jun 29;22(6):e19786 [FREE Full text] [doi: 10.2196/19786] [Medline: 32540845]

27. Mann DM, Chen J, Chunara R, Testa PA, Nov O. COVID-19 transforms health care through telemedicine: Evidence from the field. J Am Med Inform Assoc 2020 Jul 01;27(7):1132-1135 [FREE Full text] [doi: 10.1093/jamia/ocaa072] [Medline: 32324855]

28. Medina M, Babiuch C, Card M, Gavrilescu R, Zafirau W, Boose E, et al. Home monitoring for COVID-19. Cleve Clin J Med 2020 Jun 11;87(5):1-4 [FREE Full text] [doi: 10.3949/ccjm.87a.ccc028] [Medline: $\underline{32409432}$ ]

29. Naik BN, Gupta R, Singh A, Soni SL, Puri GD. Real-Time Smart Patient Monitoring and Assessment Amid COVID-19 Pandemic - an Alternative Approach to Remote Monitoring. J Med Syst 2020 Jun 13;44(7):131 [FREE Full text] [doi: 10.1007/s10916-020-01599-2] [Medline: 32533379]

30. Petrocelli M, Ruggiero F, Baietti AM, Pandolfi P, Salzano G, Salzano FA, et al. Remote psychophysical evaluation of olfactory and gustatory functions in early-stage coronavirus disease 2019 patients: the Bologna experience of 300 cases. J Laryngol Otol 2020 Jul 28;134(7):571-576. [doi: 10.1017/s0022215120001358]

31. Saleem J, Read J, Loehr B, Frisbee KL, Wilck NR, Murphy JJ, et al. Veterans' response to an automated text messaging protocol during the COVID-19 pandemic. J Am Med Inform Assoc 2020 Aug 01;27(8):1300-1305 [FREE Full text] [doi: 10.1093/jamia/ocaa122] [Medline: 32470974]

32. Schinköthe T, Gabri MR, Mitterer M, Gouveia P, Heinemann V, Harbeck N, et al. A Web- and App-Based Connected Care Solution for COVID-19 In- and Outpatient Care: Qualitative Study and Application Development. JMIR Public Health Surveill 2020 Jun 01;6(2):e19033 [FREE Full text] [doi: 10.2196/19033] [Medline: 32406855]

33. Song X, Liu X, Wang C. The role of telemedicine during the COVID-19 epidemic in China-experience from Shandong province. Crit Care 2020 Apr 28;24(1):178 [FREE Full text] [doi: 10.1186/s13054-020-02884-9] [Medline: 32345359]

34. Sossai P, Uguccioni S, Casagrande S. Telemedicine and the 2019 coronavirus (SARS-CoV-2). Int J Clin Pract 2020 Oct 08;74(10):e13592 [FREE Full text] [doi: 10.1111/ijcp.13592] [Medline: 32563197]

35. Timmers T, Janssen L, Stohr J, Murk J, Berrevoets M. Using eHealth to Support COVID-19 Education, Self-Assessment, and Symptom Monitoring in the Netherlands: Observational Study. JMIR Mhealth Uhealth 2020 Jun 23;8(6):e19822 [FREE Full text] [doi: 10.2196/19822] [Medline: $\underline{\text { 32516750] }}$

36. Vaira LA, Salzano G, Petrocelli M, Deiana G, Salzano FA, De Riu G. Validation of a self-administered olfactory and gustatory test for the remotely evaluation of COVID-19 patients in home quarantine. Head Neck 2020 Jul 09;42(7):1570-1576 [FREE Full text] [doi: 10.1002/hed.26228] [Medline: $\underline{\text { 32357379] }}$

37. Sharma M, Sharma S, Singh G. Remote monitoring of physical and mental state of 2019 -nCoV victims using social internet of things, fog and soft computing techniques. Comput Methods Programs Biomed 2020 Nov;196:105609. [doi: 10.1016/j.cmpb.2020.105609] [Medline: 32593062]

38. Xu H, Huang S, Qiu C, Liu S, Deng J, Jiao B, et al. Monitoring and Management of Home-Quarantined Patients With COVID-19 Using a WeChat-Based Telemedicine System: Retrospective Cohort Study. J Med Internet Res 2020 Jul 02;22(7):e19514 [FREE Full text] [doi: 10.2196/19514] [Medline: 32568727]

39. Huang S, Xiao Y, Yan L, Deng J, He M, Lu J, et al. Implications for Online Management: Two Cases with COVID-19. Telemed J E Health 2020 Apr;26(4):487-494. [doi: 10.1089/tmj.2020.0066] [Medline: 32233973]

40. Alwashmi MF. The Use of Digital Health in the Detection and Management of COVID-19. Int J Environ Res Public Health 2020 Apr 23;17(8):2906 [FREE Full text] [doi: 10.3390/ijerph17082906] [Medline: 32340107]

41. Crawford A, Serhal E. Digital Health Equity and COVID-19: The Innovation Curve Cannot Reinforce the Social Gradient of Health. J Med Internet Res 2020 Jun 02;22(6):e19361 [FREE Full text] [doi: 10.2196/19361] [Medline: 32452816]

42. Fagherazzi G, Goetzinger C, Rashid MA, Aguayo GA, Huiart L. Digital Health Strategies to Fight COVID-19 Worldwide: Challenges, Recommendations, and a Call for Papers. J Med Internet Res 2020 Jun 16;22(6):e19284 [FREE Full text] [doi: 10.2196/19284] [Medline: 32501804]

43. Hong Z, Li N, Li D, Li J, Li B, Xiong W, et al. Telemedicine During the COVID-19 Pandemic: Experiences From Western China. J Med Internet Res 2020 May 08;22(5):e19577 [FREE Full text] [doi: 10.2196/19577] [Medline: 32349962]

44. Horowitz RI, Freeman PR. Three novel prevention, diagnostic, and treatment options for COVID-19 urgently necessitating controlled randomized trials. Med Hypotheses 2020 Oct;143:109851 [FREE Full text] [doi: 10.1016/j.mehy.2020.109851] [Medline: $\underline{32534175}$ ]

45. Kannampallil T, Ma J. Digital Translucence: Adapting Telemedicine Delivery Post-COVID-19. Telemed J E Health 2020 Sep 01;26(9):1120-1122. [doi: 10.1089/tmj.2020.0158] [Medline: 32427529]

46. Keshvardoost S, Bahaadinbeigy K, Fatehi F. Role of Telehealth in the Management of COVID-19: Lessons Learned from Previous SARS, MERS, and Ebola Outbreaks. Telemed J E Health 2020 Jul 23;26(7):850-852. [doi: 10.1089/tmj.2020.0105] [Medline: 32329659] 
47. Massaroni C, Nicolò A, Schena E, Sacchetti M. Remote Respiratory Monitoring in the Time of COVID-19. Front Physiol 2020 May 29;11:635 [FREE Full text] [doi: 10.3389/fphys.2020.00635] [Medline: 32574240]

48. Ming LC, Untong N, Aliudin NA, Osili N, Kifli N, Tan CS, et al. Mobile Health Apps on COVID-19 Launched in the Early Days of the Pandemic: Content Analysis and Review. JMIR mHealth uHealth 2020 Sep 16;8(9):e19796 [FREE Full text] [doi: 10.2196/19796] [Medline: 32609622]

49. Sharma T, Bashir M. Use of apps in the COVID-19 response and the loss of privacy protection. Nat Med 2020 Aug 26;26(8):1165-1167. [doi: 10.1038/s41591-020-0928-y] [Medline: 32457443]

50. Thulesius H. Increased importance of digital medicine and eHealth during the Covid-19 pandemic. Scand J Prim Health Care 2020 Jun 02;38(2):105-106. [doi: 10.1080/02813432.2020.1770466] [Medline: $\underline{\text { 32484725] }}$

51. Watson AR, Wah R, Thamman R. The Value of Remote Monitoring for the COVID-19 Pandemic. Telemed J E Health 2020 Sep 01;26(9):1110-1112. [doi: 10.1089/tmj.2020.0134] [Medline: 32384251]

52. Ye J. The Role of Health Technology and Informatics in a Global Public Health Emergency: Practices and Implications From the COVID-19 Pandemic. JMIR Med Inform 2020 Jul 14;8(7):e19866 [FREE Full text] [doi: 10.2196/19866] [Medline: $\underline{32568725]}$

53. Cohen JK. Remote monitoring helps keep low-acuity COVID-19 patients at home. Modern Healthcare. URL: https://www. pressreader.com/usa/modern-healthcare/20200420/281840055803238 [accessed 2021-04-11]

54. Edelman L, McConnell E, Kennerly S, Alderden J, Horn S, Yap T. Mitigating the Effects of a Pandemic: Facilitating Improved Nursing Home Care Delivery Through Technology. JMIR Aging 2020 May 26;3(1):e20110 [FREE Full text] [doi: 10.2196/20110] [Medline: 32412909]

55. Greenhalgh T, Wherton J, Shaw S, Morrison C. Video consultations for covid-19. BMJ 2020 Mar 12;368:m998. [doi: 10.1136/bmj.m998] [Medline: 32165352]

56. John O. Video consultations for triage of patients with covid-19. BMJ 2020 Apr 23;369:m1583. [doi: 10.1136/bmj.m1583] [Medline: $\underline{32327408]}$

57. Greenhalgh T, Koh GCH, Car J. Covid-19: a remote assessment in primary care. BMJ 2020 Mar 25;368:m1182. [doi: 10.1136/bmj.m1182] [Medline: 32213507]

58. Japan ECMOnet for COVID-19. Japan ECMOnet for COVID-19: telephone consultations for cases with severe respiratory failure caused by COVID-19. J Intensive Care 2020 Apr 7;8(1):24 [FREE Full text] [doi: 10.1186/s40560-020-00440-9] [Medline: 32288941]

59. Barsom EZ, Feenstra TM, Bemelman WA, Bonjer JH, Schijven MP. Coping with COVID-19: scaling up virtual care to standard practice. Nat Med 2020 May 14;26(5):632-634. [doi: 10.1038/s41591-020-0845-0] [Medline: 32405054]

60. Fitz Maurice M, di Tommaso F, Baranchuk A. Efecto de una intervención en las redes sociales en tiempos del COVID-19. Medicina. URL: https://www.medicinabuenosaires.com/indices-de-2020/volumen-80-ano-2020-no-3-indice/carta efecto/ [accessed 2021-04-11]

61. Giansanti D, Aprile I. Is the COVID-19 Pandemic an Opportunity to Enlarge the Telemedicine Boundaries? Telemed J E Health 2020 Sep 01;26(9):1123-1125. [doi: 10.1089/tmj.2020.0159] [Medline: $\underline{\text { 32456559] }}$

62. Hau YS, Kim JK, Hur J, Chang MC. How about actively using telemedicine during the COVID-19 pandemic? J Med Syst 2020 Apr 30;44(6):108 [FREE Full text] [doi: 10.1007/s10916-020-01580-z] [Medline: 32350626]

63. Jamil B. Clinical features, diagnosis and management of COVID-19 patients in the outdoor setting. J Pak Med Assoc 2020 May;70(Suppl 3)(5):S52-S55. [doi: 10.5455/JPMA.12] [Medline: 32515378]

64. Nair SC, Satish KP, Sreedharan J, Muttappallymyalil J, Ibrahim H. Improving Health Literacy Critical to Optimize Global Telemedicine During COVID-19. Telemed J E Health 2020 Nov 01;26(11):1325-1325. [doi: 10.1089/tmj.2020.0175] [Medline: $\underline{32463318}$ ]

65. Trethewey SP, Beck KJ, Symonds RF. Video consultations in UK primary care in response to the COVID-19 pandemic. Br J Gen Pract 2020 May;70(694):228-229. [doi: 10.3399/bjgp20X709505] [Medline: 32354807]

66. Wei Y, Li G, Li J, Chu J, Yue H, Zhang F, et al. Outpatient strategies and the changing SARS-CoV-2 epidemic. ERJ Open Res 2020 Apr 17;6(2):00111-2020 [FREE Full text] [doi: 10.1183/23120541.00111-2020] [Medline: 32440516]

67. Mann DM, Chen J, Chunara R, Testa PA, Nov O. COVID-19 transforms health care through telemedicine: Evidence from the field. J Am Med Inform Assoc 2020 Jul 01;27(7):1132-1135 [FREE Full text] [doi: 10.1093/jamia/ocaa072] [Medline: 32324855]

68. Hunter A, Facey K, Thomas V, Haerry D, Warner K, Klingmann I, et al. EUPATI Guidance for Patient Involvement in Medicines Research and Development: Health Technology Assessment. Front Med (Lausanne) 2018 Sep 6;5:231 [FREE Full text] [doi: 10.3389/fmed.2018.00231] [Medline: 30238004]

69. Noah B, Keller MS, Mosadeghi S, Stein L, Johl S, Delshad S, et al. Impact of remote patient monitoring on clinical outcomes: an updated meta-analysis of randomized controlled trials. NPJ Digit Med 2018;1:20172 [FREE Full text] [doi: 10.1038/s41746-017-0002-4] [Medline: 31304346]

70. Su D, Michaud TL, Estabrooks P, Schwab RJ, Eiland LA, Hansen G, et al. Diabetes Management Through Remote Patient Monitoring: The Importance of Patient Activation and Engagement with the Technology. Telemed J E Health 2019 Oct 01;25(10):952-959. [doi: 10.1089/tmj.2018.0205] [Medline: 30372366] 
71. Jain VK, Iyengar K, Vaish A, Vaishya R. Differential mortality in COVID-19 patients from India and western countries. Diabetes Metab Syndr 2020 Sep;14(5):1037-1041 [FREE Full text] [doi: 10.1016/j.dsx.2020.06.067] [Medline: 32640415]

72. Moore JT, Ricaldi JN, Rose CE, Fuld J, Parise M, Kang GJ, COVID-19 State, Tribal, Local, and Territorial Response Team. Disparities in Incidence of COVID-19 Among Underrepresented Racial/Ethnic Groups in Counties Identified as Hotspots During June 5-18, 2020 - 22 States, February-June 2020. MMWR Morb Mortal Wkly Rep 2020 Aug 21;69(33):1122-1126 [FREE Full text] [doi: 10.15585/mmwr.mm6933e1] [Medline: 32817602]

73. Muñoz-Price LS, Nattinger AB, Rivera F, Hanson R, Gmehlin CG, Perez A, et al. Racial Disparities in Incidence and Outcomes Among Patients With COVID-19. JAMA Netw Open 2020 Sep 01;3(9):e2021892 [FREE Full text] [doi: 10.1001/jamanetworkopen.2020.21892] [Medline: $\underline{\text { 32975575] }}$

\section{Abbreviations \\ RMT: remote monitoring technology}

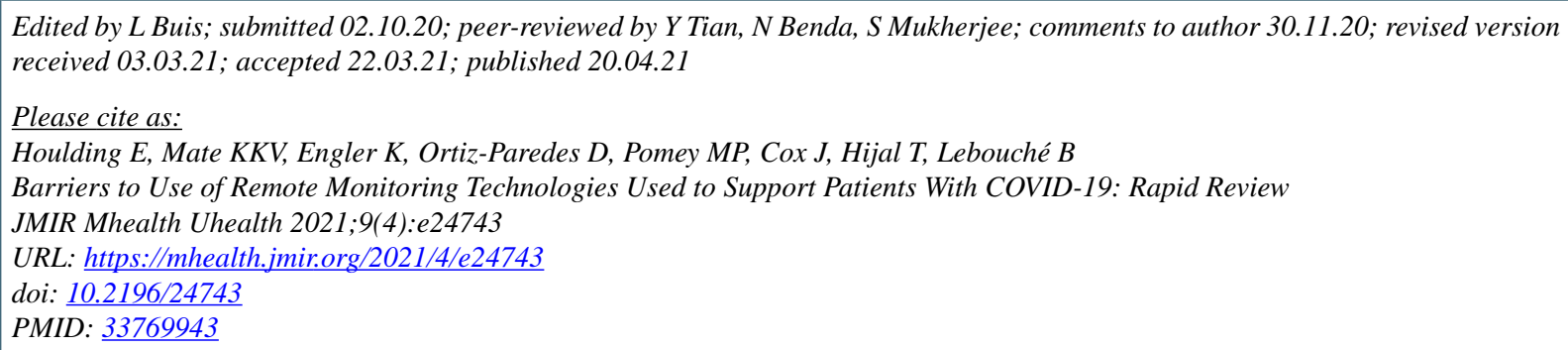

CElizabeth Houlding, Kedar K V Mate, Kim Engler, David Ortiz-Paredes, Marie-Pascale Pomey, Joseph Cox, Tarek Hijal, Bertrand Lebouché. Originally published in JMIR mHealth and uHealth (https://mhealth.jmir.org), 20.04.2021. This is an open-access article distributed under the terms of the Creative Commons Attribution License (https://creativecommons.org/licenses/by/4.0/), which permits unrestricted use, distribution, and reproduction in any medium, provided the original work, first published in JMIR mHealth and uHealth, is properly cited. The complete bibliographic information, a link to the original publication on http://mhealth.jmir.org/, as well as this copyright and license information must be included. 